\title{
Effect of Process Parameters on Tensile Strength of Friction Stir Welded Joint of Pure Copper
}

\author{
Pankaj kumar ${ }^{1}$, Satpal Singh ${ }^{2}$, Gurmeet Singh ${ }^{3}$, Ankit Dua ${ }^{4}$ \\ ${ }^{l}$ (M.Tech Student, Ganpati institute of technology, Bilaspur, Haryana) \\ ${ }^{2}$ (Lecturer, Thapar Polytechnic, Patiala, Punjab) \\ ${ }^{3}$ (Research Scholar, Thapar University, Patiala, Punjab) \\ ${ }^{4}$ (Assistant Professor, M.M. University, Sadopur-Ambala, Haryana)
}

\begin{abstract}
Article focuses the effect of the processing parameters on tensile behaviour of friction stir welded copper joints. Copper and aluminium are considered as non-weldable with the conventional techniques but this non-conventional method of joining, successfully welds these non-ferrous metals. Effect of parameters on tensile strength of copper weld joint was studied by using full factorial design matrix by considering parameters like rotational speed $(1000,2500,4000,5000 \mathrm{rpm})$ and tool travel speed $(10,30,50,60 \mathrm{~mm} / \mathrm{min})$ also keeping tool material and tool design fixed throughout the experimentation. Using full factorial total 16 numbers of experiments were performed and relative tensile strengths were measured. The results showed that increasing rotational speed helps to increases the tensile strength with in a specific range while increasing feed rate lowered the tensile strength.
\end{abstract}

Keywords - Friction stir welding, Full factorial, Pure copper, Taguchi, Tensile strength

\section{INTRODUCTION}

Friction stir welding was invented in in last decent of $20^{\text {th }}$ century by the welding institute London [13]. This technique was majorly employed to weld the non-ferrous metals which are considered to be tough weldable with conventional techniques [3]. Friction stir welding was using commercially successfully from the early years of $21^{\text {st }}$ century and evolve the world of metal joining of aluminium industry. The friction stir welding is also considered as the green welding technique because of its less energy consumption and lower heat generation during welding [4]. Technically, friction stir welding process is very simple and easy to understand. The metal pieces to be weld are fixed adjacent with abutting edges and a tool rotating to its central axis having a pin plunged up to the shoulder with in the metal travelled along the abutting edge line of both metal pieces [5]. The detailed process can be easily assessable from figure 1. Friction welding is solid state welding process in which metal dose not reach to melting stage but got weld at recrystallization temperature only. This is the reason that friction stir weld joint is free from defects like; oxidation, shrinkage or porosity [6]. The friction stir welding is also considered as cleaner welding process because of no use of any harmful gases, chemical flux or fumes. These chemicals may lead to bronchitis and o other lungs disorders in workers [6].

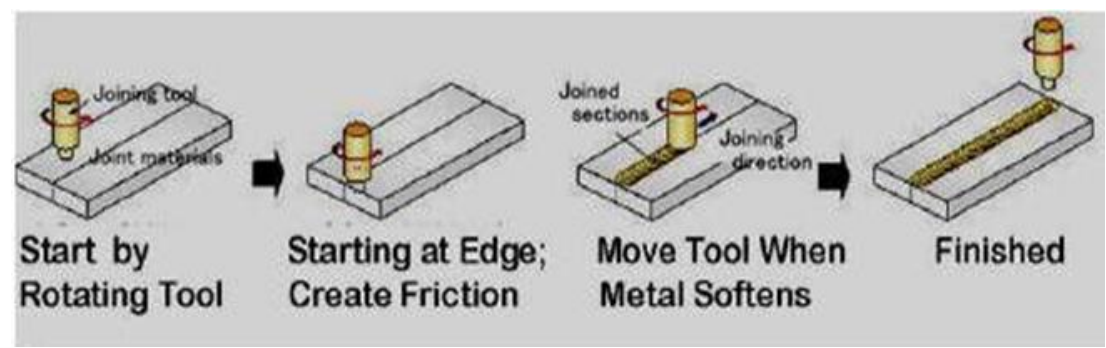

Figure 1: shows the schematic flow process of friction stir welding

Recently, friction stir welding was employed to join the different aluminium alloys and aluminium metal matrix composites successfully. Some attempt has been made to join the dissimilar aluminium alloys and aluminium alloy with low carbon steel and magnesium alloys. Tensile properties of aluminium alloys and other dissimilar joints has been evaluated in different research articles. Bisadi et al. [7] examined the effect of rotational speed and welding speeds on microstructures and mechanical properties of friction stir welded Al5083 
and commercially pure copper lap joints. They claimed that very low welding temperature leads to some defects like channels and extremely high process temperature leads to some cavities appearance. Schneider et al. [8] found that the rotational speed has a significant effect on the shape of weld zone and joint strength. However, the fracture location and mechanisms of welds were not studied, which would be of high interest in welding of the high strength Al-Li alloys. Concerning. Uzun et al. [9] reported the joint strength of friction stir welded joint of 304 stainless steel and Al 6013-T4 with thickness of plates $4 \mathrm{~mm}$ can reach approximately $70 \%$ of the base aluminum alloy. Ghosh et al. [10] investigated the FSW joint of 100\% Aluminium to 304 stainless steel and the maximum tensile strength was documented as $82 \%$ of base material. $\mathrm{Fe}_{3} \mathrm{Al}$ was found with finer grains exist in the central stirring zone, which indicate the active recrystallization of metal grains. Tanaka et al. [11] join two dissimilar metal using FSW, Al7075-T6 to mild steel of the thickness of $3 \mathrm{~mm}$. Tool rotational speed with in the range of 400 to $1200 \mathrm{rpm}$ and tool travel speed of $100 \mathrm{~mm} / \mathrm{min}$. The maximum tensile strength was observed as $333 \mathrm{MPa}$, which is about $60 \%$ of the base aluminium alloy. Moreover, there is an exponentially increasing relation between the interface strength and the reducing thickness of IMC layer, which has the composition of $\mathrm{FeAl}_{3}$. Lee et al. [12] directing experiments on FW of Al6056-T4 to 304 stainless steel with thickness of $4 \mathrm{~mm}$ with the rotational speed of $800 \mathrm{rpm}$ and welding speed of $80 \mathrm{~mm} / \mathrm{min}$. The thin intermetallic compound layer of $250 \mathrm{~nm}$ thickness was analysed through transmission electron microscopy (TEM) and identified as formation of $\mathrm{FeAl}_{4}$. Chen and Kovacevic [13] successfully weld the Al6061 to AISI 1018 steel sheet with the thickness of $6 \mathrm{~mm}$. Local melting of Aluminum was observed and shear-off steel platelets encompassed by IMC layers of Fe4Al13 and Fe2 Al15 existed in the weld nugget. Locally partial molten Aluminum was again reported by Jiang and Kovacevic [14] when they did study on the same pair of materials with the same thickness.in present article, aluminium alloy 6082 was used and effect of parameters on tensile strength was studied.

From previous studies it was found that very less studies has been conducted for copper metals. So this study focuses the effect of different parameters on tensile strength of weld joints.

\section{MATERIAL AND METHODOLOGY}

\subsection{PURE COPPER}

Material used for friction stir welding was commercially available $99 \%$ copper. Copper is widely used in the electrical industry and refrigeration and air-conditions plants. The properties of copper are shown in table 1 . These properties show its versatility among the engineering material.

Table 1: Mechanical properties of copper

\begin{tabular}{|c|c|c|c|}
\hline Young's Modulus & Shear Modulus & Poisson ratio & Hardness(HV) \\
\hline $110-128 \mathrm{MPa}$ & $48 \mathrm{GPa}$ & 0.34 & $343-369 \mathrm{MPa}$ \\
& & & \\
\hline
\end{tabular}

\subsection{TOOL MATERIAL}

Tool used for friction stir welding is made of AISI 4140 having a pin of desired length which is to be inserted to the abutting edges of metal pieces. Description of tool material shown in table 2. Figure 2 A shows the drawing of tool used and figure $2 \mathrm{~B}$ shows the tool used during the experimentation.

Table 2: Chemical composition of AISI 4140 used as tool

\begin{tabular}{|c|c|c|c|c|c|c|c|}
\hline Element & C & SI & Mn & S & P & Ni & Cr \\
\hline Wt\% & 0.40 & 0.25 & 1.0 & 0.01 & 0.017 & 0.09 & 1.10 \\
\hline
\end{tabular}



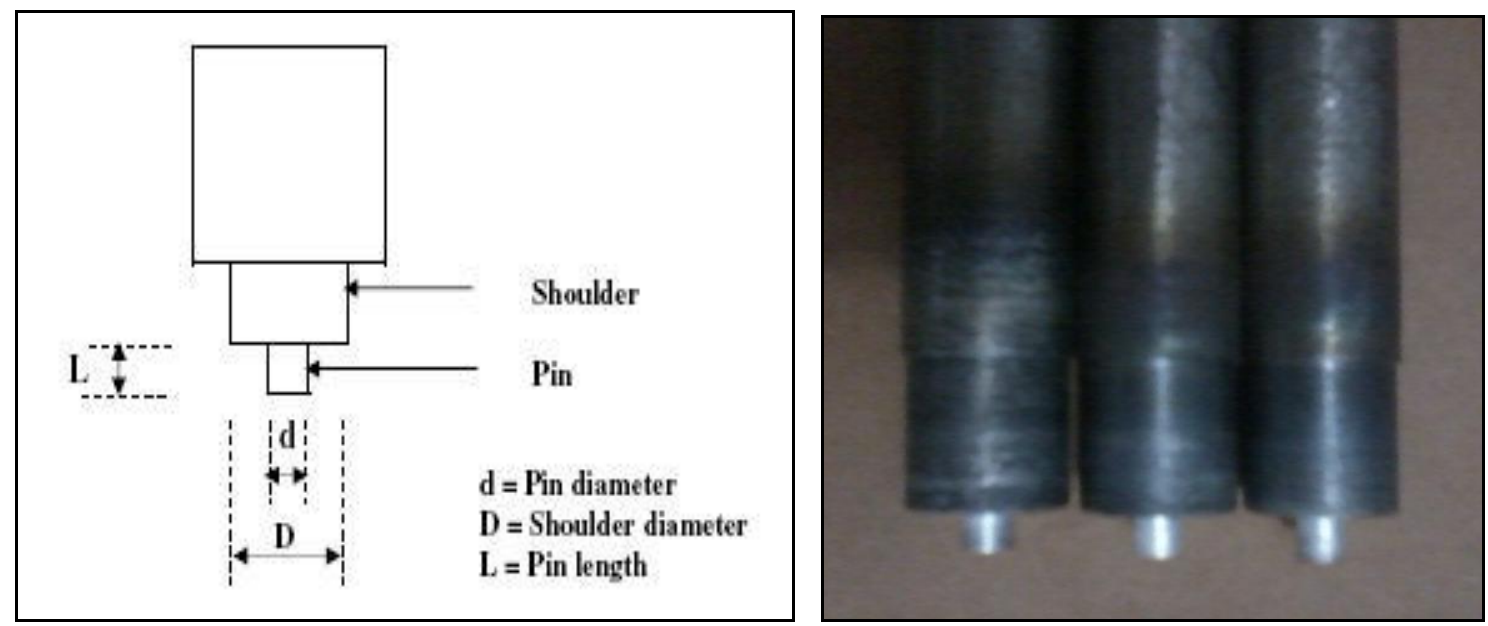

Figure 2(A and B): A- drawing for FSW tool; B- tool prepared for FSW

\subsection{PARAMETERS SELECTION}

Process parameters for friction stir welding are selected on the basis of pilot experimination. From litrature it is evident that rotational speed and travel speed are the major parameters in friction stir welding. These parameters shows the maximum contributation in terms of tensile strength of friction stir welde joints. The range of parameters selction are shown in the following table 3.

Table 3: Parameters and their levels selected through preliminary experimentation

\begin{tabular}{|c|c|c|c|c|c|c|c|}
\hline Sr.no & Parameters & Units & Range & Level1 & Level2 & Level3 & Level 4 \\
\hline 1 & Rotational speed (R) & RPM & $1000-5500$ & 1000 & 2500 & 4000 & 5500 \\
\hline 2 & Traverse speed(T) & $\mathrm{mm} / \mathrm{min}$ & $10-55$ & 10 & 25 & 40 & 55 \\
\hline
\end{tabular}

\subsection{METHODOLOGY}

Full factorial orthogonal array was used to check the optimum combination of parameters for the tensile strength of welded joint. The design matrix of 2 parameters with 4 level each. No of experiments is calclucted by simple formula $=\mathrm{n}^{\mathrm{p}}$, where $\mathrm{n}=$ no of parameters and $\mathrm{p}=$ no of levels. So according to the formula 16 no of experiments is to be performed under this full factorial design.

\section{EXPERIMENTATION}

The following steps are involved for the welding process:

A rotating tool is plundge up to the shoulder in the abutting edges of two copper plates having dimensions $150 \times 50 \times 6 \mathrm{~mm}$ (Lxbxt) respectively. These plates were placed on fixture in a manner that prevents the displacement of plates during welding and fix them along the travel line of welding tool. The velocity difference between the rotating tool and the stationary work piece, heat is produced by frictional work and deformation of copper started. This deformed material fused as a single piece create a joint. To accomplish the welding, the rotating tool is traversed along the line, while the shoulder of the tool is maintained in intimate contact with the plate surface. Shoulder confirms the underlying material so void formation and porosity behind the probe are prevented. As the heat dissipated into the surrounding material, the temperature rises and material softens without reaching the melting point (hence known as solid state process). As the pin is moved in the direction of the welding leading face of pin, assisted by a specified pin profile, forces plasticized material to the back of the pin whilst applying a substantial forging force to consolidate the weld metal. When the 
weld distance is covered, the tool is pulled out of the workpiece leaving behind an exit hole as a foot print of the tool. The following figure 3 contains the sample prepared by friction stir welding.

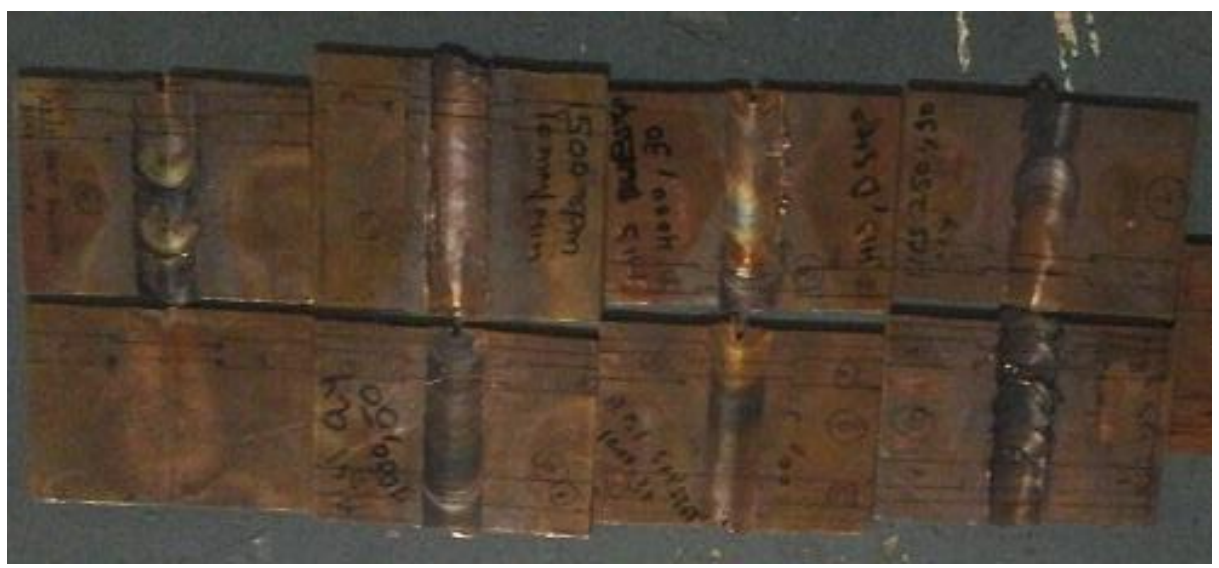

Figure 3: friction stir weld samples

\subsection{SAMPLE PREPARATION}

Ultimate tensile strength (UTS), or tensile strength (TS) or ultimate strength, is the extreme stress that a material can withstand while being stretched or pulled before necking. Tensile strength is defined as a stress, which is measured as force per unit area. This test was performed on universal testing machine. Specimen for this testing shown in Figure 5 were cut from the welded plate on power hacksaw and prepared on vertical milling machine.

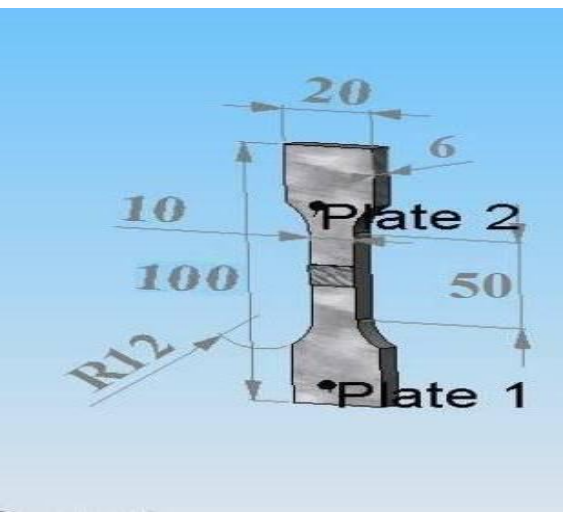

Figure 5: Design for tensile specimen

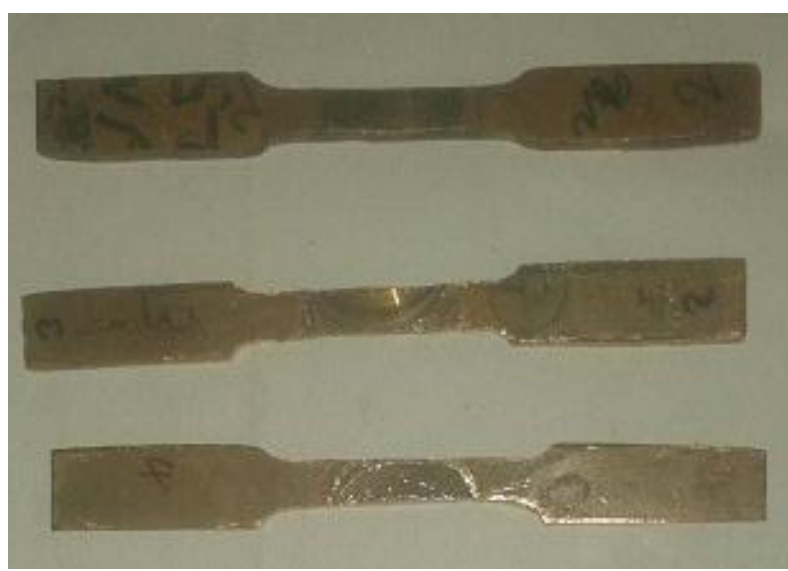

Figure 6: Sample prepared for tensile strength 


\section{RESULT AND DISCUSSION}

Total 16 experiments are performed with all possible combination of selected parameters (rotational speed, traverse speed) according to combination of parameters by full factorial design matrix. Tensile strength at desired combination of parameters are shown below in table 5. The tensile strength of FSW specimens within the range of 62 to $112 \mathrm{MPa}$. This is almost 60 to $98 \%$ of the base metal and shows the better tensile strength as compared to other welding process.

Table 5: Tensile Strength of FSW specimens welded at different set of parameters

\begin{tabular}{|c|c|c|c|}
\hline Sr. no & Rotational Speed(R) & Traverse Speed (T) & Tensile Strength \\
\hline 1 & 1000 & 25 & 82 \\
\hline 2 & 2500 & 10 & 104 \\
\hline 3 & 5500 & 40 & 89 \\
\hline 4 & 2500 & 40 & 77 \\
\hline 5 & 4000 & 10 & 110 \\
\hline 6 & 1000 & 55 & 62 \\
\hline 7 & 5500 & 25 & 104 \\
\hline 8 & 1000 & 40 & 65 \\
\hline 9 & 2500 & 25 & 89 \\
\hline 10 & 5500 & 55 & 75 \\
\hline 11 & 1000 & 10 & 92 \\
\hline 12 & 2500 & 55 & 67 \\
\hline 13 & 4000 & 40 & 112 \\
\hline 14 & 5500 & 10 & \\
\hline 15 & 4000 & 55 & \\
\hline 16 & 4000 & 25 & \\
\hline
\end{tabular}




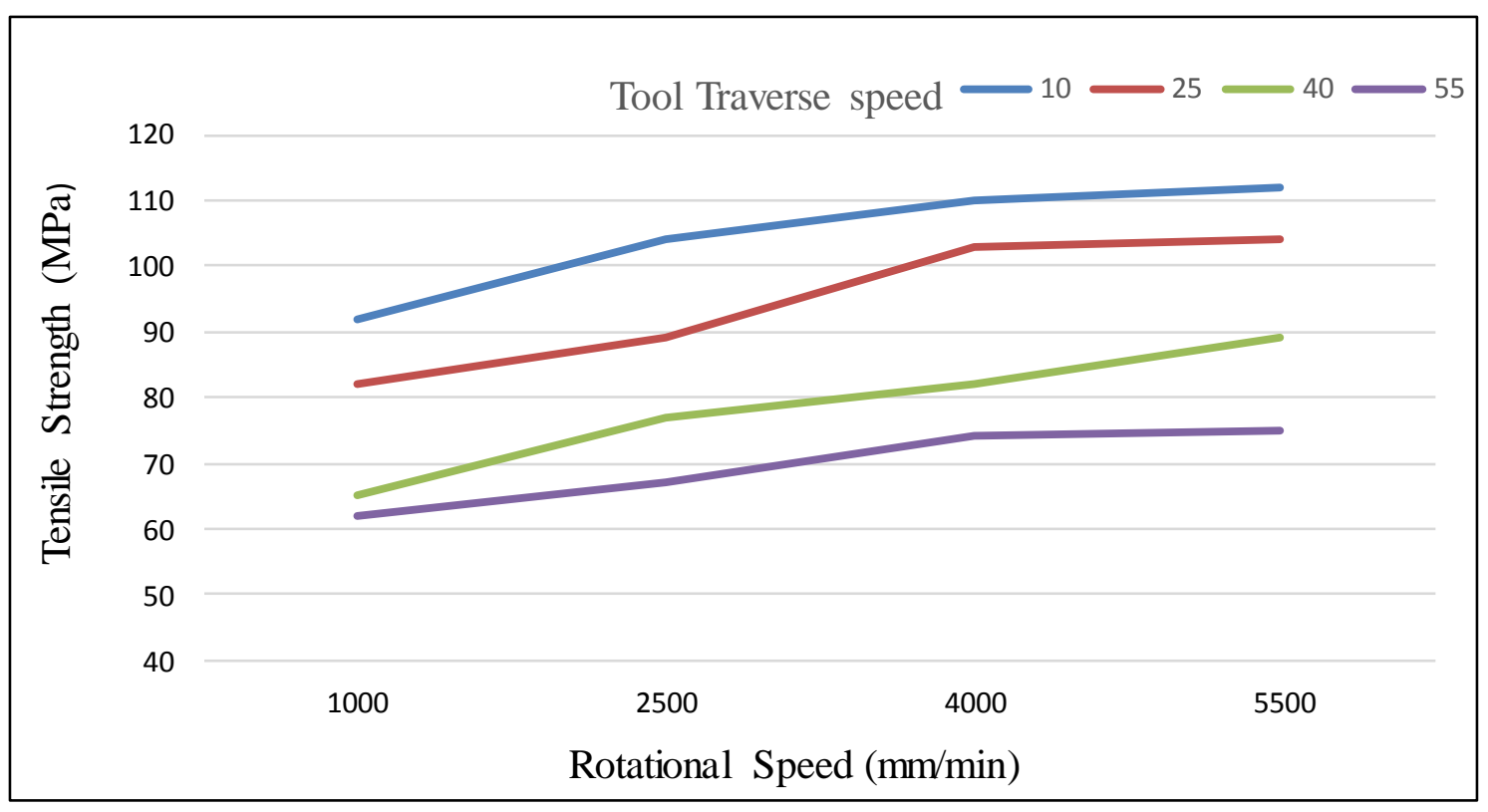

Figure 7: Tensile behaviour of FSW joints for varying rotational speed with different travel speed

From the above figure 7, it is evident that the tensile strength has a significant effect with all above stated parameters and there effect can be seen from the graphs.

\section{CONCLUSION}

Parameters involved in friction stir welding shows there effect of mechanical properties and all involved parameters can be explained as follows:

- Rotational speed of tool shows its effect on tensile strength very significantly, higher rpm gives better tensile strength, as the average tensile strength with $5000 \mathrm{rpm}$ is $95 \mathrm{MPa}$ which is higher than the tensile strength at 4000, 2500 and $1000 \mathrm{rpm}$ i.e. $92.5 \mathrm{MPa}, 84.25 \mathrm{MPa}$ and 75.25 respectively. So the rotational speed should be kept high with in the range.

- Traverse speed shows its effect and it can be seen that increasing traverse speed decreases the tensile strength. The reason behind this is, with increasing traverse speed the contact time decreases and less heat generated at that particular point and lowers the tensile strength.

- From full factorial design the optimum set of parameters is experiment no 14 . Which is maximum rotational speed (5000 rpm), lower traverse speed $(10 \mathrm{~mm} / \mathrm{min})$.

\section{REFERENCES}

[1] R.S. Mishra, Z.Y. Ma , "Friction stir welding and processing," Mater Sci Eng R-Rep, vol.50(1-2), pp.1-78, 2005.

[2] W. Thomas, P. Threadgill, E. Nicholas, "Feasibility of friction stir welding steel," Sci Technol Weld Join , vol. 4(6), pp.365-372,1999.

[3] W.M.Thomas, E.D. Nicholas, J.C. Needham, M.G. Murch, P. Temple-Smith, C.J. Dawes, "Improvements relating to friction welding" E.P. Office; 1993.

[4] Y. Abe, T. Kato, K. Mori, “Joinability of aluminium alloy and mild steel sheets by self piercing rivet.” J Mater Proc Technol, vol.177, pp.417-421, 2006.

[5] C.Y. Choi, D.C. Kim, D.G. Nam, Y.D. Kim, Y.D. Park, “A hybrid joining technique for aluminum/zinc coated steels in vehicles,” J Mater Sci Technol, vol.26, pp.858-864, 2010.

[6] W.H. Zhang, D.Q.Sun,L.J. Han, W.Q. Gao, X.M. Qiu, "Characterization of intermetallic compounds in dissimilar material resistance spot welded joint of high strength steel and aluminium alloy,” ISIJ Int, vol.51, pp. 1870-1877,2011.

[7] Bisadi, H., Tavakoli, A., Sangsaraki, M.T., Sangsaraki, K.T., 2013. The influences of rotational and welding speeds on microstructures and mechanical properties of friction stir welded A15083 and commercially pure copper sheets lap joints. Mater. Des. 43, 80-88.

[8] J.A. Schneider, A.C. Nunes, M.S. Brendel, The influence of friction stir weld tool form and welding parameters on weld structure and properties: nugget bulge in self-reacting friction stir welds, In: 8th International Symposium on Friction Stir Welding, May 18-20, Timmendorfer Strand (Germany), 2010. 
[9] H. Uzun, C. Dalle Donne, A. Argagnotto, T. Ghidini, C. Gambaro, "Friction stir welding of dissimilar Al 6013-T4 To X5CrNi18-10 stainless steel," Mater Des, vol. 26, pp. 41-46,2005.

[10] M. Ghosh, A. Kar, K. Kumar, S. Kailas, "Structural characterisation of reaction zone for friction stir welded aluminium-stainless steel joint,” Mater Technol: Adv Perform Mater, vol.27,pp.169-172, 2012.

[11] T. Tanaka, T. Morishige, T. Hirata, "Comprehensive analysis of joint strength for dissimilar friction stir welds of mild steel to aluminum alloys,” Scripta Mater, vol.61, pp.756-759,2009.

[12] W-B. Lee, M. Schmuecker, U.A. Mercardo, G. Biallas, S-B. Jung, "Interfacial reaction in steel-aluminum joints made by friction stir welding,” Scripta Mater ,vol.55, pp.355-358, 2006.

[13] C.M. Chen, R. Kovacevic, "Joining of Al 6061 alloy to AISI 1018 steel by combined effects of fusion and solid state welding," "Int J Machine Tools Manuf," vol. 44, pp.1205-1214, 2004.

[14] R. Kovacevic,W.H. Jiang, "Feasibility study of friction stir welding of 6061-T6 aluminium alloy with AISI 1018 steel," J Eng Mnauf, vol.218, pp.1323-1331, 2004. 